\title{
Regional patterns in technological progress of Poland: the role of EU structural funds
}

\author{
Henryk Gurgul ${ }^{1} \cdot$ Lukasz $^{\text {Lach }^{1}}$
}

\begin{abstract}
To the best of our knowledge, this paper is one of the first studies to analyze the evolution and determinants of regional patterns in the technological progress of one of the new EU members in transition-Poland. The results of the first part of the study prove that, after EU accession, the central region was the only part of Poland that not only reported a rapid rise in labor productivity but also managed to constantly increase its capital productivity. In the second part of the empirical analysis, we conduct a formal econometric analysis aimed at testing whether these differences in regional patterns in the technological progress of Poland could be caused by the inflow of EU structural funds.
\end{abstract}

Keywords Technological progress · Intranational catching-up · Transition economies $\cdot$ EU structural funds

JEL Classification D24 $\cdot$ J24 $\cdot$ R12

\section{Introduction}

The aim of this paper is twofold. First, we analyze the differences in the evolution of the regional and voivodeship technological progress across the various regions of

\footnotetext{
$凶$ Henryk Gurgul

henryk.gurgul@gmail.com

http://www.zarz.agh.edu.pl/gurgul/

Łukasz Lach

llach@ zarz.agh.edu.pl;

http://www.zarz.agh.edu.pl/1lach/

1 Department of Applications of Mathematics in Economics, Faculty of Management, AGH University of Science and Technology, Gramatyka 10 St., 30-067 Kraków, Poland
} 
Poland-a Central and Eastern European (CEE) transition country that accessed to the European Union in the first years of the twenty-first century. Second, using formal econometric methods, we try to answer the main research question of this paper; i.e., we try to verify whether the inflow of EU structural funds could be one of the forces behind the post-EU-accession evolution of regional patterns in the technological progress of Poland.

The motivation to analyze the case of the Polish economy is also twofold. First, Poland is the largest economy in the CEE region and one of the economic and political leaders in the region. In addition, a thorough examination of the evolution and determinants of the regional patterns of technological change in Poland has not been conducted so far (to the best of our knowledge). In particular, little attention has been paid to the impact of the inflow of EU structural funds on the process of regional technological progress. On the other hand, uncovering the forces behind the differences in the regional patterns of technological change is crucial for a better understanding of the process of intranational economic catching-up ${ }^{1}$ of the less developed regions in Poland.

In this way, our paper fills a gap in the literature and provides results that may prove important for both researchers and policymakers in Poland as well as other post-communist economies. In this context, one must emphasize that, at the very beginning of the transition, public opinion in Poland (especially in the poorer and less developed areas of the country) mostly represented the point of view that the transition should bring new opportunities and lead to an essential reduction of the disparities in the economic development of different Polish regions. Moreover, after a quarter of a century of transition, Poland was often called a model transition economy where shock therapy was successfully applied. ${ }^{2}$ However, recent data shows that most of the measures of the various aspects of the differences in the economic development of Polish regions have been constantly rising during the whole transition period, also since EU accession (Gurgul and Lach 2011). Furthermore, there has been little evidence that the allocation of EU structural funds brought about faster economic growth and income convergence in the less developed regions of the old EU15 members, like Germany or Italy. ${ }^{3}$ The latter may suggest that the EU regional policy realized via structural funds is mostly a re-distributive mechanism rather than an efficient tool designed to foster economic convergence (Lobatch 2004; Gorzelak 2006). Therefore, besides describing the regional patterns in the technological progress of Poland, it also seems interesting to examine whether the inflow of EU structural funds could be one of the forces behind these changes. To the best of our knowledge, there are currently no studies that on the one hand describe the evolution of region-specific patterns in the technological change

\footnotetext{
${ }^{1}$ In the research context of this paper, the term catching-up is understood as the growing equality in the distribution of labor and capital productivity over the investigated periods among the Polish regions and within them (i.e., among the Polish voivodeships).

2 This view is often expressed by both researchers (e.g., Lenain 2000) as well as politicians (recall US President Barack Obama hailing Poland as a model of transition during his visit to Warsaw in 2011-for details, see http://www.huffingtonpost.com/2011/05/28/obama-poland-democracy_n_868434.html).

3 Comp. the lack of noticeable catching-up in the case of Southern Italy (Mezzogiorno) or the German eastern lands.
} 
in Poland within the framework of the efficiency schedule and on the other hand try to formally test the role of the inflow of EU structural funds on shaping the regional changes in productivity in the country being studied.

The content of this paper is as follows. Section 2 provides a brief literature review. Section 3 presents the main research hypotheses examined in this paper. The dataset and methodology of the research are presented in Sect. 4. The main empirical results are provided in Sect. 5. Finally in Sect. 6, we summarize the major findings and suggest general directions for future research.

\section{Literature review}

The rising interest in the process of economic growth in the CEE economies in transition has been observed from the very beginning of the 1990s. In the literature, there are some papers that focus on the topic of the regional differences in economic growth, the dynamics of inequality, and the problem of economic convergence in different countries of the region (Gurgul and Lach 2011; Czyż and Hauke 2011, among others). As discussed in the previous section, many researchers and politicians claim that, although Poland constitutes a textbook example of successful transition, it has also experienced uneven regional development, which makes it of particular interest as a case-study country in the CEE region. To summarize, it is not surprising that the overall economic development of the CEE transition economies in recent decades, being accompanied by noticeable regional disparities (also after their EU accession), has attracted a lot of interest. In this section, we will briefly review the previous literature, paying special attention to those studies that focus solely on the Polish economy. In this context, one may claim that the empirical findings of our paper supplement the papers reviewed since these studies discussed the role of the inflow of EU structural funds on the evolution of regional productivity in Poland mostly from a theoretical perspective. ${ }^{4}$

The two main research questions of this paper are as follows: What has the evolution of regional patterns in the technological progress of Poland been in recent decades? Is there any formal evidence that this process was partly driven by the inflow of EU structural funds? Interestingly, the pursuit of an answer to these questions attracted the attention of researchers even before Poland's EU accession. In one of the very first studies dealing with these two research problems, Lobatch (2004) analyzed empirical data from Poland and the EU as well as the findings of other researchers. The goal of the research was to investigate the regional disparities in Poland and discuss the potential impact of EU regional policy. The study outlined the possible strategy options regarding the allocation of EU transfers and assessed positive, neutral, and negative scenarios for each option.

In the opinion of Lobatch (2004), the equity-efficiency dilemma in Poland after EU accession should be resolved in favor of efficiency. In this case, those regions that are

\footnotetext{
4 In recent years, the links between various aspects of regional productivity and EU regional policy/institutional background have been a subject of intensive research in both the theoretical and empirical dimensions (comp. e.g., Kramulová and Jablonský 2016; Di Cataldo 2017; Chocholatá and Furková 2017, among others). However, in this context, one must stress the lack of empirical studies dealing with the case of CEE transition economies (e.g., Poland).
} 
performing well may become locomotives of growth and simply continuously pull the lagging regions forward. The government in this case should not seek to maximize the amount of EU money but rather attract investments and pursue tight fiscal discipline in the first instance and next make sure that the peripheral regions benefit from the spread of economic growth arising in the most productive regions.

Similarly to Lobatch (2004) also Gorzelak (2006) did not expect that the inflow of EU funds would support the essential reduction of the regional disparities among the Polish regions, as the physical, social, and economic aspects of these disparities are the effects of long duration processes that are rather fixed in character and are very difficult to change through external influences. Gorzelak (2006) also emphasized that, although the vast EU funds available could change the spatial development, it is unlikely that they could change the mental structures, attitudes, and behavior of the population at the same time (as proven by the history of the unsuccessful catching-up of the former German Democratic Republic).

However, Gorzelak (2006) stressed (contrary to Lobatch (2004)) that the simple strategy of opting for more effectiveness and less equity may not be an optimal policy for Poland. This is because the lasting regression of certain regions (not only in relative but also absolute terms, as could be seen in eastern Poland) forces the authorities to embark upon activities that are not always rational in terms of narrowly understood economic effectiveness but are intended to improve the situation in the less developed regions. Such efforts in turn will most likely fail to accelerate economic growth, and their effects will be observed mainly in the social sphere.

It must be emphasized that, due to the lack of sufficient datasets, previous studies could neither describe in detail the evolution of the regional patterns in the technological progress of Poland nor answer the question as to whether there is any statistical evidence that these changes were partly driven by the inflow of EU structural funds. ${ }^{5}$ Filling both of these gaps in the literature is one of the main goals of our study.

\section{Main research hypotheses}

Looking at the history of the development of some Western European economies, one may claim that regional inequalities increase at first as economic development proceeds but then tend to slightly decline once a certain level of national economic development has been reached (Atkinson and Morelli 2014). However, as suggested by Gurgul and Lach (2011), it is likely that Poland has not achieved the turning point as of yet with respect to regional inequalities. Moreover, at the turn of the twenty-first century, the central region was ranked first among Poland's regions (leaving the remaining regions far behind) in the total value of industrial output and in terms of the amount of investments made by foreign sources. ${ }^{6}$ The latter was mainly

\footnotetext{
5 Recent literature on the potential determinants of regional disparities in Poland is rather extensive (comp. e.g., the papers by Gurgul and Lach (2011) and Czyż and Hauke (2011) and the cited pieces therein). However, studies that examine the role of the inflow of EU structural funds on the evolution of regional patterns in the technological progress of Poland are still lacking.

6 According to the Central Statistical Office in Poland, the average inflow of FDI per capita in the central region was equal to $136 \%$ of the country's average during the years of 2010-2015. On the other hand, this
} 
caused by the industrial activity centered in the Warsaw Industrial District, where domestic and foreign companies have their headquarters. In addition, the majority of state enterprises are headquartered in Poland's capital-Warsaw. Moreover, the number of universities and other educational institutions in Warsaw is the highest among all Polish cities. To summarize, in the central region of Poland, the necessary capital and highly qualified labor are both easy accessible. All of these facts allow us to expect the central region to experience a Hicks-neutral technological change ${ }^{7}$ and strengthen its position as a solo leader in terms of productivity among all Polish regions. To summarize, one may expect that the regional differences in productivity in Poland could become even deeper in the upcoming decades. All of these remarks in turn suggest that the following hypothesis may hold true:

Hypothesis 1 From the very beginning of the transition, the central region of Poland has experienced a Hicks-neutral technological change. Moreover, as compared to the remaining regions, capital productivity and labor productivity have risen much faster in this region. These phenomena intensified after Poland's EU accession.

The methodology applied in this paper allows us to not only describe the historical data but also draw some conclusions about the evolution of the regional distributions of capital productivity and labor productivity in Polish voivodeships in the near future. Taking into account the results of a visual inspection of the recent regional data on Poland and the suggestions expressed in the previous hypothesis, we can formulate the following conjecture:

Hypothesis 2 During the transition period, the regional distributions of capital productivity and labor productivity in Poland showed a tendency to move towards a bi-modal pattern with a club formation at the high ends of the distributions. The latter suggests that, in the upcoming years of Polish EU membership, this bi-modality is expected to become even more evident.

As already mentioned, the analysis of economic growth and income convergence in the less developed regions in the old EU15 members provides little evidence that the allocation of EU structural funds has turned out to be an efficient tool in fostering economic convergence (Lobatch 2004; Gorzelak 2006). To the best of our knowledge there are no studies that analyze the role of the EU structural funds in shaping the evolution of regional patterns in the technological progress of Poland. Thus, we may assume that, in the case of this economy, the nature of the causal links discussed will be similar to the historical experience of the old EU15 members. Therefore, we can formulate the following final hypothesis:

Hypothesis 3 The EU structural funds were a statistically significant cause (in Granger's sense) of the evolution of regional patterns in the technological progress of

Footnote 6 continued

indicator reached a level of only $70 \%$ of the country's average in the eastern region, which was the lowest value among all Polish regions.

7 Technological change is said to be Hicks-neutral if it is neither capital-saving nor labor-saving. In other words, this type of technological change is neutral in its effect in the sense that neither of the two factors (capital, labor) become more or less important at the margin. 
Poland and led to an intensification in the bi-modality pattern in the distributions of capital productivity and labor productivity. The strongest stimulating effect of the EU structural funds on labor and capital productivity was observed in the central region of Poland.

In the next section, we will introduce the dataset and describe the methodology used in the empirical part of the paper.

\section{Data and methodology}

This section begins with a detailed description of the dataset used. We provide information on the data sources along with a description of all of the transformations of the original dataset. Then, we explain the three major analytical concepts of the study; i.e., the derivation of the wage-profit schedule that we next use for analyzing the patterns of regional technological change and the modified discrete distribution dynamics approach based on the use of homogenous and non-homogenous discrete-time Markov chains. Finally, we introduce the methodology of testing for Granger causality from the inflow of EU structural funds to three regional-productivity-related indexes.

\subsection{Dataset and initial data transformations}

We analyze 16 Polish voivodeships that belong to the six regions. Figure 1 provides a reference map of Poland with all of the voivodeships and regions indicated.

As mentioned in the introductory section, the main variables examined in this study are the inflow of EU structural funds, gross value added, employment, and net fixed capital stock. The nominal data of all variables was taken directly from the Local Data Bank. ${ }^{8}$ The inflow of European funds corresponds to the total value of funding from EU operational programs transferred to Polish voivodeships. The gross value added corresponds to the gross regional product during each year for each voivodeship. We define employment as the total number of employed persons in each year and for each voivodeship. In the later parts of the paper, we use a panel dataset on the voivodeship level in Poland spanning the period of 1995-2015.

Wages are derived from the data on the compensation of employees in each year and for each voivodeship. All monetary variables available in the Local Data Bank are expressed in the current prices in PLN. ${ }^{9}$ To correct the nominal values of the inflow of EU structural funds, gross value added, and wages for price changes, we deflate them by using the voivodeship-specific GDP-deflators obtained from the Local Data Bank. Henceforth, we shall refer to the voivodeship-level data on the real inflow of EU structural funds, real gross value added, and real wages expressed in terms of 1995

\footnotetext{
8 The Local Data Bank is Poland's largest database of the economy and households, innovation, public finance, society, demographics, and the environment. The database is maintained by the Central Statistical Office in Poland. It offers more than 40,000 statistical variables collected in more than 30 thematic categories. The bank contains data dating back to 1995 .

9 PLN is the official abbreviation of the Polish currency - the Polish zloty.
} 


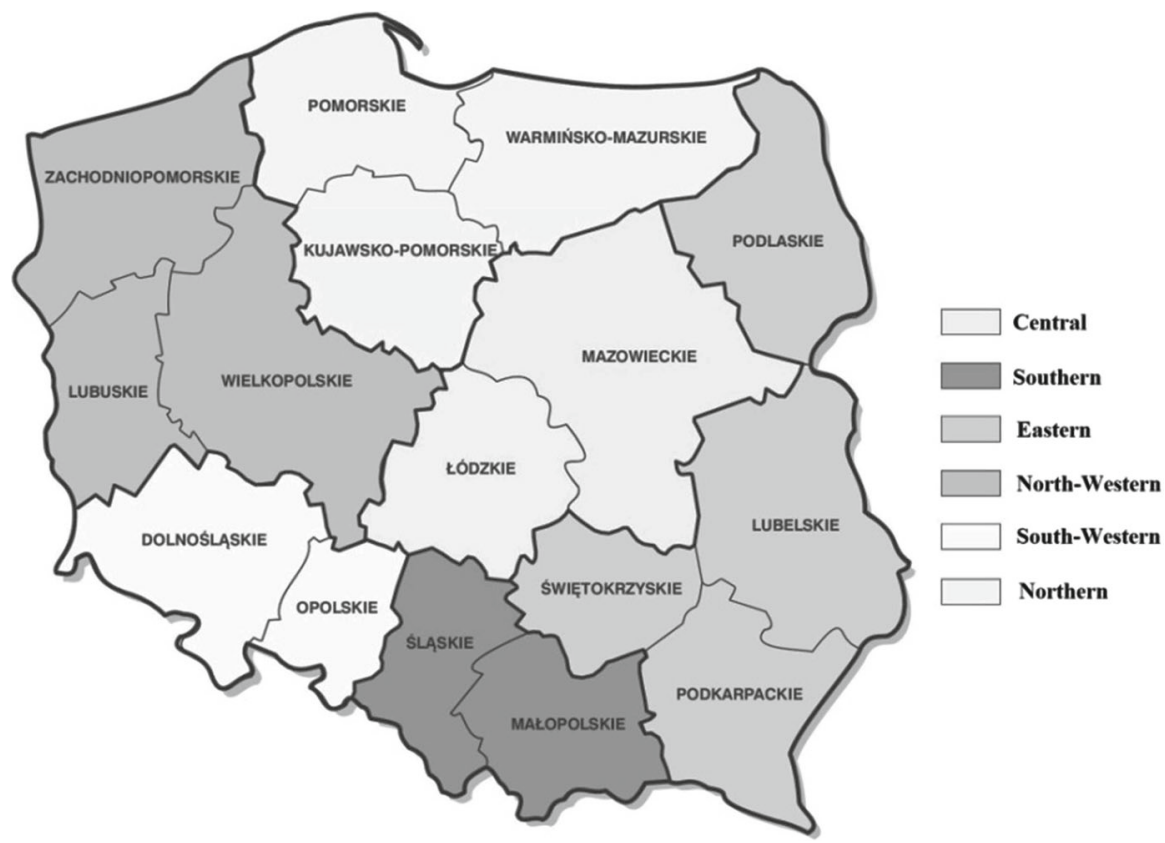

Fig. 1 Division of Poland by regions and voivodeships Source Central Statistical Office of Poland

(real gross value added and real wages) and 2010 (real inflow of EU structural funds) prices. ${ }^{10}$

To calculate the fixed capital stock, we follow the arguments of Schütz et al. (2017) and use the well-known perpetual inventory method (PIM) introduced by Goldsmith (1951). For period $t$ and voivodeship $j$, let $K_{t}^{j}$ denote the real capital stock, $I_{t}^{j}$ denote the level of fixed investment, and $\delta_{t}^{j}$ denote the depreciation rate. The PIM is calculated using the following equation:

$$
K_{t}^{j}=K_{t-1}^{j}\left(1-\delta_{t}^{j}\right)+I_{t}^{j}
$$

As an approximation of the level of fixed investment in Eq. (1), we use data on gross fixed capital formation (which is also available in the Local Data Bank). For the price deflator of the series of gross fixed capital formation, we use the voivodeship price index in the construction sector. ${ }^{11}$ We follow the arguments of Grabek et al. (2011) and set the annual voivodeship-level depreciation rate at a level of $9.6 \%$. Henceforth,

\footnotetext{
10 Except for the inflow of EU structural funds, the period of 1995-2015 was the longest one for which reliable data on all of the selected regional economic indicators was available in official statistical agendas in Poland at the time of preparing the paper. In the case of the inflow of EU structural funds, the period of 2010-2015 was the longest one for which reliable data for the Polish voivodeships was available.

11 The motivation for using this specific type of price index to construct the deflators of fixed capital formation is twofold. First, the Local Data Bank and other databases provided by the Central Statistical Office do not contain official statistics on the voivodeship nor the regional price index of fixed capital formation. Second, it seems reasonable to assume that, due to the nature of fixed assets (which to a large
} 
we shall refer to voivodeship-level data on real fixed capital formation expressed in 1995 prices.

\subsection{Evaluating regional differences in technological change}

In this paper, we investigate the intranational catching-up process of Polish regions in terms of the nature and direction of regional technological change. For this purpose, we use the concept of the efficiency schedule introduced by Foley and Marquetti (1997) and Foley and Michl (1999) to identify the relationship between wages and profits for the six Polish regions. ${ }^{12}$ To shed some light on this concept, let $V A_{t}^{r}$ be the aggregate value added at time $t$ in region $r$. From an income-based viewpoint, regional aggregate value added can be split into the following:

$$
V A_{t}^{r}=W_{t}^{r}+Z_{t}^{r},
$$

where $W_{t}^{r}$ stands for the wages (compensation of employees) and $Z_{t}^{r}$ denotes the regional capital compensation (i.e., gross profits), which consists of non-wage income (i.e., net profits $R_{t}^{r}$ ) and depreciation $D_{t}^{r}$ (i.e., $Z_{t}^{r}=R_{t}^{r}+D_{t}^{r}$ ). Also, let $L_{t}^{r}$ stand for total employment measured by the number of employed persons at time $t$. Then, from (2) and the definition of $Z_{t}^{r}$, one may easily obtain the following relationship expressed in per capita terms:

$$
\frac{W_{t}^{r}}{L_{t}^{r}}=\frac{V A_{t}^{r}}{L_{t}^{r}}-\frac{Z_{t}^{r}}{L_{t}^{r}}=\frac{V A_{t}^{r}}{L_{t}^{r}}-\frac{R_{t}^{r}}{L_{t}^{r}}-\frac{D_{t}^{r}}{L_{t}^{r}} .
$$

A simple algebraic transformation allows one to rewrite (3) in the following form:

$$
\frac{W_{t}^{r}}{L_{t}^{r}}=\frac{V A_{t}^{r}}{L_{t}^{r}}-\left(\frac{R_{t}^{r}}{K_{t}^{r}} \frac{K_{t}^{r}}{L_{t}^{r}}\right)-\left(\frac{D_{t}^{r}}{K_{t}^{r}} \frac{K_{t}^{r}}{L_{t}^{r}}\right) .
$$

If one denotes the per capita quantities as $w_{t}^{r}=\frac{W_{t}^{r}}{L_{t}^{r}}, v a_{t}^{r}=\frac{V A_{t}^{r}}{L_{t}^{r}}, k_{t}^{r}=\frac{K_{t}^{r}}{L_{t}^{r}}, r_{t}^{r}=\frac{R_{t}^{r}}{L_{t}^{r}}$, $z_{t}^{r}=\frac{Z_{t}^{r}}{L_{t}^{r}}$ and $\delta_{t}^{r}=\frac{D_{t}^{r}}{L_{t}^{r}}$, then (4) takes the following form:

$$
w_{t}^{r}=v a_{t}^{r}-k_{t}^{r}\left(r_{t}^{r}+\delta_{t}^{r}\right)=v a_{t}^{r}-k_{t}^{r} z_{t}^{r} .
$$

Footnote 11 continued

extent cover buildings and other types of construction), the price index in the construction sector seems to be the most suitable approximation of the price index among all of the available alternatives.

12 The efficiency schedule for an economy (a line that has output per worker or labor productivity as its horizontal intercept, and output per unit of capital or capital productivity as its vertical intercept) is a method of visualizing patterns of economic growth and technical changes over time (Foley and Marquetti 1997). Among others, this concept has also been used by Ferretti (2008), Vaona (2011), and Schütz et al. (2017). 
Based on (5), one may formalize the concept of the efficiency schedule. Economic interpretation of the latter builds upon the classical idea of the inverse relationship between the profit rate $\left(z_{t}^{r}\right)$ and wage rate $\left(w_{t}^{r}\right)$. The slope coefficient in the linear relationship (5) is given by the capital-labor ratio $\left(k_{t}^{r}\right)$. After some simple algebraic transformations, one may conclude that the vertical intercept in (5) corresponds to the maximum gross profit rate or equivalently to capital productivity and is given by formula $\tilde{z}_{t}^{r}=V A_{t}^{r} / K_{t}^{r}$. The horizontal intercept corresponds to the maximum wage rate (or equivalently to labor productivity, defined as $\tilde{w}_{t}^{r}=V A_{t}^{r} / L_{t}^{r}$ ). Using (5), one may compare the shifts in the efficiency schedule for each of the six Polish regions over time and subsequently contrast the results of this comparison with the analysis of the dynamics of inequality among the spatial distribution of the economic variables being studied. This in turn allows one to discuss the nature of the technological change during the observation period and its role in the intraregional catching-up in Poland in transition. In particular, one may focus on three types of regional technological change:

- a counter-clockwise shift in the efficiency schedule along its vertical intercept, which implies a purely labor-saving technological change,

- a clockwise shift in the efficiency schedule along its horizontal intercept, which implies a purely capital-saving technological change,

- a parallel outward shift in the efficiency schedule, indicating a Hicks-neutral technological change.

Figure 2 illustrates the three special cases of technological progress outlined above.

\subsection{Discrete distribution dynamics and process of catching-up}

In addition to the first method introduced in Subsection 4.2, we outline the second concept of examining the catching-up process among Polish regions and voivodeships in this subsection. We use the discrete distribution dynamics (DDD) approach introduced and further investigated by Quah (1993a, 1996a, b, 1997), which we apply in order to study the process of the catching-up of Polish voivodeships in terms of voivodeship capital productivity and labor productivity dynamics. ${ }^{13}$ DDD allows us to focus on the entire shape of the distribution of the variable being studied as well as the intertemporal changes therein. The latter is one of the main advantages of DDD over the regression approach, which is capable of providing only some summary statistics on the distribution of the variable of interest. ${ }^{14}$ Yet, by attributing such a conclusion, this might provoke Galton's fallacy; this is prevented if the distribution dynamics approach is used. ${ }^{15}$ Another important fact is that, contrary to the regression approach, the DDD

\footnotetext{
13 The DDD approach is an alternative to the traditional examination of beta- and sigma-convergence by means of regression analysis (Barro and Sala-i-Martin 1991, 1992; Gurgul and Lach 2011). Also, see Islam (2003) for an excellent literature overview on the different approaches to measuring convergence.

14 For example, Quah (1993a) stresses that a negative regression parameter in the traditional betaconvergence model does not per se point towards a reduction in divergence.

15 The term Galton's Fallacy has more than one meaning. The term has been used to denote the problems encountered when the neoclassical convergence model is tested in a cross-section of a country's GNP his-
} 

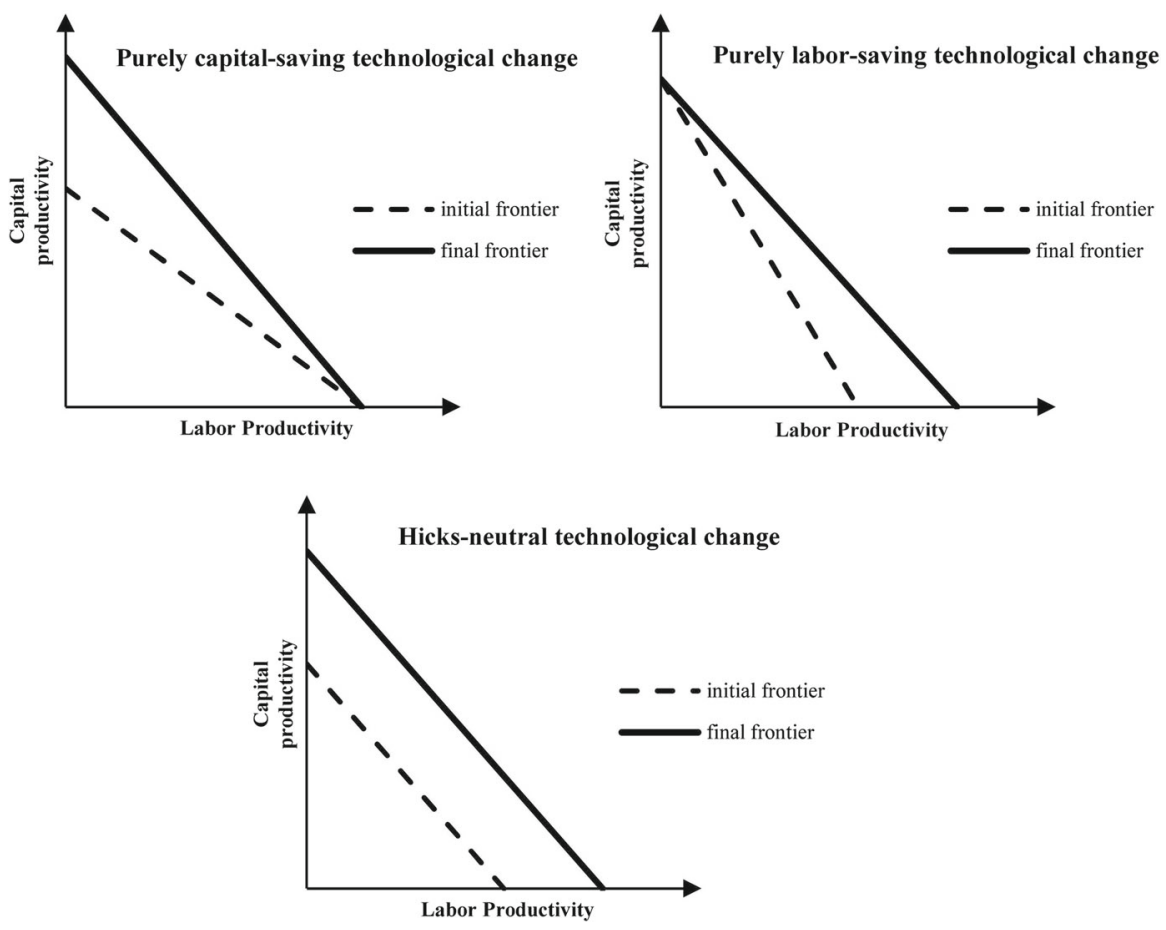

Fig. 2 Using efficiency schedule to describe different types of technological change Source Own elaborations based on Foley and Marquetti (1997)

approach allows us to study convergence processes without the need to build solely upon the neoclassical growth theory but instead to discriminate between the alternative growth theories.

To shed some light on our approach to studying the distributional dynamics of capital (labor) productivity within the DDD framework, let us start with some general remarks on the variables used in this part of the research. For the $j$-th voivodeship in Poland $(j=1, \ldots, 16)$, let $\overline{\bar{z}}_{t}^{j}\left(\overline{\bar{w}}_{t}^{j}\right)$ stand for the normalized voivodeship capital productivity (normalized labor productivity) at time $t$. The latter is obtained by dividing the capital productivity (labor productivity) by its national average given by the cross-section mean (henceforward denoted as $\bar{z}_{t}^{j}\left(\bar{w}_{t}^{j}\right)$ ); i.e.:

$$
\overline{\bar{z}}_{t}^{j}=\frac{z_{t}^{j}}{\bar{z}_{t}}\left(\overline{\bar{w}}_{t}^{j}=\frac{w_{t}^{j}}{\bar{w}_{t}}\right) .
$$

\footnotetext{
Footnote 15 continued

tories (Barrow-Baumol regressions). Friedman (1992) and Quah (1993b) independently identify problems that they separately call Galton's Fallacy. However, Friedman (1992) and Quah (1993b) mean different things by the term. Once the nature of various Galton fallacies has been clarified, it is possible to elucidate some issues of econometric estimation that may be encountered in economic convergence regression estimation (Bliss 1999).
} 
Both normalized variables defined in (6) are continuous and take non-negative values. However, due to the relatively small size of the sample available, we focus only on the discrete approach in this paper; i.e., instead of a direct analysis of the variables defined in (6), we first discretize their parameter spaces. This type of discretization requires us to define a finite number of states to represent the distribution of each variable. ${ }^{16}$ For the purpose of clarity in our presentation of the DDD approach, let $x_{t}$ denote one of the discretized normalized productivities (i.e., capital or labor productivity defined in (6)) at time $t$. For every $t$ variable $x_{t}$ may take one of $n$ different states. Also, let $F_{t}$ denote the cross-sectional distribution of $x_{t}$. As stressed by Durlauf and Quah (1998) and Bulli (2001), the simplest model that could be used to describe the law of motion of the cross-sectional distribution between time $t$ and $t+s$ is given by the following first-order autoregressive process:

$$
F_{t+s}=A_{t, s}\left(F_{t}\right)
$$

where $A_{t, s}$ is an operator mapping the transition of $F_{t}$ to $F_{t+s}$. Given the fact that the distribution $F_{t}$ is discrete for each $t$, one may easily reinterpret (7) and express the law of motion using Markov transition probability $M^{t, s}=\left[m_{k l}^{t, s}\right]_{k, l=1, \ldots, n}$ of dimension $n \times n$. For a one-step transition, this representation takes the following form: ${ }^{17}$

$$
F_{t+1}=\left(M^{t, 1}\right)^{\prime} F_{t}
$$

Each element $m_{k l}^{t, 1}$ corresponds to the (conditional) probability of moving one step from state $k$ to state $l$ between time $t$ and $t+1 .^{18}$ If we assume the stationarity of the transitional probability matrix over time (time-homogeneity of the transition mechanism; i.e., $M^{t, s}=M=\left[m_{k l}\right]_{k, l=1, \ldots, n}$ for all $\left.t, s>0\right)$, then the distribution of $x_{t}$ after $s$ periods is given by the following:

$$
F_{t+s}=\underbrace{M^{\prime}\left(M ^ { \prime } \left(\ldots(M)^{\prime}\right.\right.}_{s \text { times }} F_{t}))=\left(M^{s}\right)^{\prime} F_{t} .
$$

Let us now recall two basic theorems on time-homogenous Markov chains. If the Markov chain defined in (9) is irreducible, then there exists a unique invariant (steadystate, ergodic) distribution $F_{\infty}=\left[F_{\infty}^{l}\right]_{l=1, \ldots, n}$ such that:

$$
F_{\infty}=(M)^{\prime} F_{\infty}
$$

\footnotetext{
16 In the literature, there is no common procedure for this type of discretization. One may define the single states by grouping the actual values of the normalized variable of interest into only quantiles and quintiles (Quah 1993a) or choose the boundaries of the grids for the variable of interest relative to the benchmark (Quah 1996a). Alternatively, Magrini (1999) uses the histogram of the cross-sectional distribution to choose the grids.

17 Throughout this paper, symbol $A^{\prime}$ stands for the transposition of matrix $A$.

18 It is clear that, for every $k, l \in\{1, \ldots, n\}, m_{k l} \geq 0$, and for every $k \in\{1, \ldots, n\}$, we have $\sum_{l=1}^{n} m_{k l}=1$.
} 
Moreover, if the chain is also aperiodic, then there exists a limiting distribution of the transition mechanism that also converges to $F_{\infty}$ (Norris 1998); i.e.,

$$
\lim _{n \rightarrow \infty} m_{k l}^{n}=F_{\infty}^{l}
$$

where $l=1, \ldots, n$ and $M^{n}=\left[m_{k l}^{n}\right]_{k, l=1, \ldots, n}$. The key feature of the methodology described is that one may draw conclusions about the distributional dynamics of variable $x_{t}$ based on an examination of the transition probabilities matrix together with an analysis of the properties of ergodic distribution $F_{\infty}$. To be more precise, if $F_{\infty}$ tends towards a mass-point, this signalizes the convergence of $x_{t}$ (i.e., convergence of capital or labor productivity) across the Polish voivodeships. On the contrary, if $F_{\infty}$ approaches bi- or multi-modality, it also signalizes the divergence of capital productivity (labor productivity) and potentially also polarization and club formation. Finally, persistence is characterized by a lack of change in the relative positions.

In order to estimate the time-homogenous Markov chains, we use maximumlikelihood-based estimators. If $n_{i j}$ denotes the number sequences (moving from state $i$ to $j$ ) found in the sample, the maximum likelihood (ML) estimator of the $m_{i j}$ entry in Markov matrix $M=\left[m_{i j}\right]_{i, j=1, \ldots, n}$ is given by the following formula (Anderson and Goodman 1957):

$$
\hat{m}_{i j}^{M L E}=\frac{n_{i j}}{\sum_{u=1}^{n} n_{i u}},
$$

with the standard error given as:

$$
s e_{i j}^{M L E}=\frac{\hat{m}_{i j}^{M L E}}{\sqrt{n_{i j}}} .
$$

Besides the ML estimator given in (12), we also use two additional estimators. Such an approach gives us the opportunity to check the stability of the ML estimators. First, we use the Laplace smoothing approach (which is a variation of the MLE) where each $n_{i j}$ is substituted by $n_{i j}+\lambda$, with $\lambda$ being an arbitrary positive stabilizing parameter; i.e.:

$$
\hat{m}_{i j}^{L S}=\frac{n_{i j}+\lambda}{\sum_{u=1}^{n}\left(n_{i u}+\lambda\right)} .
$$

In general, the motivation for considering Laplace smoothing follows from the fact that a sparse matrix may arise if the Markov chain observed is relatively short. This in turn suggests that some transitions are impossible (which may be unlikely in certain cases).

The last method of estimating time-homogenous Markov chains is based on bootstrapping the data. The bootstrap procedure applied in this paper follows these steps:

- bootstrap the data sequences following the conditional distributions of the states estimated from the original one (denote the number of bootstrap samples as $n_{b o o t}$ ),

- apply an ML estimator (12) on each of the $n_{b o o t}$ bootstrapped data sequences, 
- calculate the $\hat{m}_{i j}^{B O O T S T R A P}$ as the average of all $\hat{m}_{i j}^{M L E}$ across all the $n_{b o o t}$ bootstrapped sequences, normalized by row; calculate the standard error of $\hat{m}_{i j}^{B O O T S T R A P}$ using the formula for the sample variance of the mean of the independent variables.

One of the central assumptions of using a first-order Markov chain approach is that there is time-homogeneity; hence, the transition probabilities (as those given in matrix $M$ ) are assumed to be constant over the whole time horizon. However, as mentioned in Bickenbach and Bode (2001), this property often turns out to be a too-restrictive assumption, which is hardly fulfilled by the actual data-generating processes. Moreover, the respective $\chi^{2}$-based parametric tests for the validity of the assumption of time-homogeneity may turn out to have very poor small sample properties (Bickenbach and Bode 2003). Thus, it is not surprising that, in such a case, more and more researchers are deciding to drop the extremely restrictive assumption of time-homogeneity and follow alternative research scenarios. ${ }^{19}$ We fit into this new research trend as well; instead of using the three types of ML-based estimators of timehomogenous Markov models, we use non-homogenous discrete-time Markov chains that we estimate via the maximum a posteriori method (MAP) implemented using Bayesian inference. ${ }^{20}$ In this way, we obtain MAP estimators of the annual transition matrices $M^{t, 1}$ defined in (8) for every $t$.

\subsection{Analysis of role of EU structural change on evolution of regional patterns in technological progress}

The methods described in Sects. 4.2 and 4.3 provide useful tools for describing the evolution of regional patterns in the technological progress of Poland. However, one also needs to conduct a formal econometric analysis that could help explain the driving factors behind the evolution of capital and labor productivity across all Polish regions and voivodeships. In particular, such tools could help verify whether these changes were caused by the inflow of EU structural funds.

For the purpose of such an analysis in this paper we conduct a series of Granger causality tests using panel VAR (PVAR) models in a generalized method of moments (GMM) framework. In general, we consider three bivariate homogeneous PVARs of order $p$ with panel-specific fixed effects. ${ }^{21}$ Each of these three models is represented by the following system of linear equations:

\footnotetext{
19 For example, Hierro and Maza (2010) calculate time-dependent, non-stationary transition probability matrices using the Chapman-Kolmogorov equation.

20 In order to save space, we do not provide all the technical details of this estimation technique. The reader may find an extensive description of the underlying methodology in Strelioff et al. (2007), for example.

21 We follow the arguments of Gelman (2005) who recommends using fixed effects whenever the sample exhausts the population. In other words, we assume that the conclusions resulting from the PVAR models may be interpreted only in the case of the Polish regions/voivodeships, not the broader set of all EU regions. Alternatively, one may use the formal Hausman specification test to choose between the FE and RE models. However, the latter is a parametric test and, thus, does not have good small-sample properties.
} 


$$
\begin{gathered}
Y_{r, t}=Y_{r, t-1} A_{1}+Y_{r, t-2} A_{2}+\ldots+Y_{r, t-p+1} A_{p-1}+Y_{r, t-p} A_{p}+X_{r, t} B+u_{r, t}+e_{r, t} \\
r \in\{1,2, \ldots, 6\}, t \in\{2010,2011, \ldots, 2015\},
\end{gathered}
$$

where:

- $Y_{r, t}$ is a $(1 \times 2)$ vector of dependent variables for region $r$ and year $t$; the first element in $Y_{r, t}$ is one of the three regional productivity-related indexes (i.e., labor productivity, capital productivity, or capital-labor ratio), while the second element in $Y_{r, t}$ is the measure of the inflow of EU structural funds,

- $X_{r, t}$ is a $(1 \times l)$ vector of the exogenous covariates,

- $u_{r, t}$ and $e_{r, t}$ are $(1 \times 2)$ vectors of the dependent variable-specific panel fixed-effects and idiosyncratic errors, respectively.

Various estimators based on GMM have been proposed to calculate consistent estimates of model (15), especially when $T$ is relatively small compared to $N$ (which is the case for the dataset being studied). ${ }^{22}$ What is particularly important is that a joint estimation of system of Eq. (15) makes cross-equation hypothesis testing straightforward. Wald tests about the parameters may be implemented based on a GMM estimate of the matrix of the parameters and its covariance matrix. Granger causality tests, with the hypothesis that all coefficients on the lag of impulse variable (inflow of EU structural funds in our case) are jointly zero in the equation for the effect variable (one of the three regional-productivity-related indexes), may likewise be carried out using this test. $^{23}$

\section{Empirical results}

This section consists of three subsections. First, for each of six Polish regions, we derive the respective wage-profit schedule that we next use for analyzing the time evolution of the patterns of regional technological change. Next, we use the modified discrete distribution dynamics approach based on the use of homogenous and nonhomogenous discrete-time Markov chains. After describing the regional technological change among the Polish regions, we try to formally verify whether these changes could be caused by a non-uniform distribution of the inflow of EU structural funds in the last subsection. ${ }^{24}$

\footnotetext{
22 Comp. the analytical bias correction for the least squares dummy variable model (Bun and Carree 2005) with the bias correction based on bootstrap methods (Everaert and Pozzi 2007). The methods applicable for random coefficient panel VAR models were reviewed by Canova and Ciccarelli (2013).

23 STATA's package pvar (Abrigo and Love 2016) allows one to estimate system of models (15) and conduct respective Granger causality tests.

24 During the period of 2010-2015, relatively large shares in the total inflow of EU structural funds were reported in the southern $(19.25 \%)$, central $(19.15 \%)$, northern (18.9\%), and north-western (16.9\%) regions of Poland. On the other hand, the relatively low shares of this index were found in the southwestern $(13.1 \%)$ and eastern (12.7\%) regions of Poland.
} 

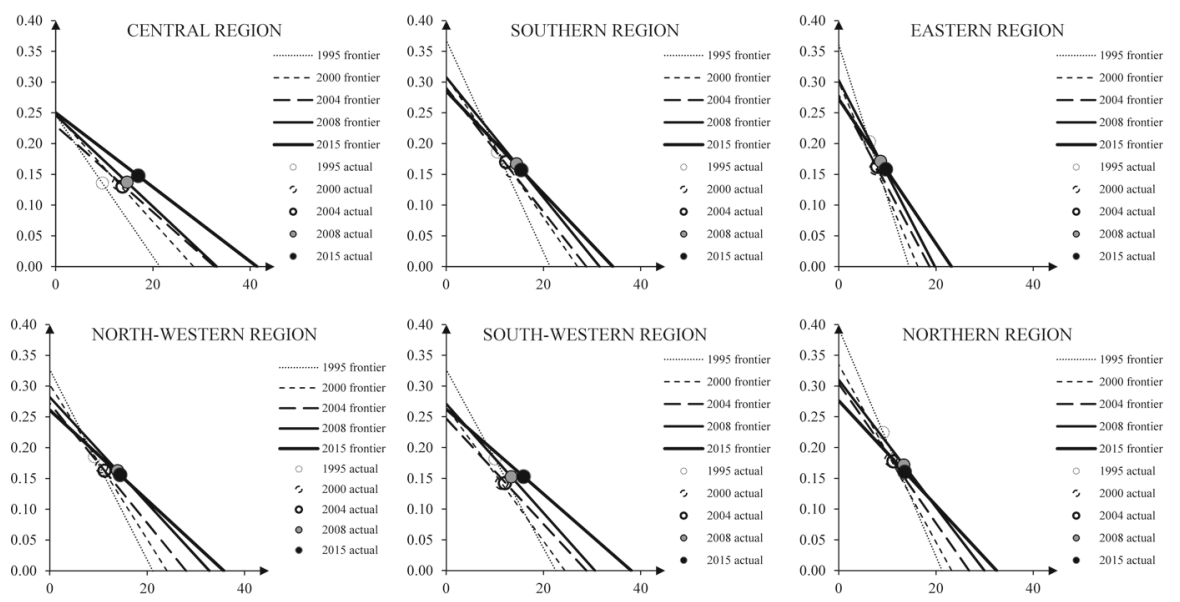

Fig. 3 Evolution of efficiency frontiers in Polish regions during period of 1995-2015 (horizontal axis: labor productivity; vertical axis: capital productivity) Source Own elaborations based on data collected from Local Data Bank

\subsection{Description of patterns in regional technological change in Poland during period of 1995-2015}

This subsection presents the results of the geometric analysis of the intertemporal shifts in the efficiency schedule (see Sect. 4.2) in six Polish regions over the period of 1995-2015. Figure 3 illustrates the corresponding regional efficiency schedules defined in Sect. 4.2 for five selected years as well as the actual unit wage-gross profit rate combinations.

To better visualize the regional patterns of technological change, both the lines (indicating the efficiency schedules) as well as the dot points (indicating the actual unit wage-gross profit rate combinations) in Fig. 3 were drawn using different line and filling styles, moving from a thin dotted line (corresponding to the data points of 1995) to a solid thick line (corresponding to the most recent data points).

At first glance, the region-specific results suggest a clear dominance of one single pattern of technological change, as the changes in production technologies were mostly of a labor-saving and capital-using nature for the entire period in five out of the six regions analyzed. However, the central region was the only region where a different pattern occurred. It is interesting that the latter was observed only after Poland's EU accession. The latter indicated that, after 2004, the technological change in the central region shifted the efficiency schedule outwards in an almost parallel fashion, causing not only a constant increase in labor productivity (as in the case of the five remaining sectors) but also an increase in capital productivity.

To summarize, the results presented in this subsection provide support for Hypothesis 1 . However, when discussing the results of verifying Hypothesis 1, two remarks need to be made. First, a Hicks-neutral technological change was observed in the central region of Poland after EU accession but not before. Second, for nearly all of the regions, capital productivity and labor productivity were not only lower than in the 
central region, they actually dropped in certain cases. In addition, labor productivity in the central region grew at a significantly higher rate than that of the remaining regions of Poland after EU accession.

\subsection{Analysis of trends in distributions of capital and labor productivity}

In this part of the empirical analysis, we study in detail the process of the catching-up of Polish voivodeships in terms of voivodeship capital productivity and labor productivity dynamics in the framework of discrete distribution dynamics. We focus on an analysis of the entire shape of the distributions of capital productivity and labor productivity as well as the intertemporal changes therein. In the research context of our paper (where we are restricted by a small sample size), the discretization grids were defined in such a way that ensured that a uniform initial distribution of labor and capital productivity would be obtained. Since our analysis concentrates on the case of four states for both the normalized capital productivity and labor productivity defined in (6), the discretization was based on the values of the quartiles of normalized capital productivity and labor productivity in the initial year (1995). Thus, we refer to the following states of normalized capital (labor) productivity at time $t$ in the following parts of this subsection:

- LOW if normalized capital (labor) productivity lies in $\left[0, q_{1}\right.$ )

- LOWER-MIDDLE if normalized capital (labor) productivity lies in $\left[q_{1}, q_{2}\right.$ )

- UPPER-MIDDLE if normalized capital (labor) productivity lies in $\left[q_{2}, q_{3}\right.$ )

- HIGH if normalized capital (labor) productivity lies in $\left[q_{3},+\infty\right)$,

where $q_{i}$ for $i=1, \ldots, 3$ stands for the $q_{i}$-th quartile of normalized capital (labor) productivity in 1995 .

Table 1 presents the results of the maximum likelihood estimations (see formulas (12) and (13)) of three models of time-homogenous Markov chains constructed for normalized capital productivity in the Polish voivodeships during the periods of 1995-2004 (pre-EU-accession period), 2004-2015 (post-EU-accession period), and 1995-2015 (full sample).

As one can see, the values of the transition probabilities on the main diagonal are highest irrespective of the period examined, which indicates that some persistence in the cross-sectional distribution of capital productivity occurred. If we focus on the results obtained for the pre-EU-accession and post-EU-accession periods, one can see that the values of the transition probabilities at the two tails (LOW and HIGH values) showed a downward trend when compared to the other main-diagonal elements. On the other hand, an opposite phenomenon took place in the case of the two middle classes. Moreover, one notices that, after EU accession, the probability of moving from the LOW to the LOWER-MIDDLE class as well as from the HIGH to the UPPER-MIDDLE class significantly rose and became much higher than the corresponding probabilities of moving in the opposite directions. All of these findings indicate that, after EU accession, the distribution of capital productivity among all Polish voivodeships underwent a transformation towards a more concentrated pattern. 
Table 1 Evolution of transition probability matrices in time-homogenous Markov chains constructed for normalized capital productivity in Polish voivodeships

\begin{tabular}{|c|c|c|c|c|}
\hline & LOW & $\begin{array}{l}\text { LOWER- } \\
\text { MIDDLE }\end{array}$ & $\begin{array}{l}\text { UPPER- } \\
\text { MIDDLE }\end{array}$ & $\mathrm{HIGH}$ \\
\hline \multirow{3}{*}{ LOW } & 0.91 & 0.09 & 0 & 0 \\
\hline & 0.82 & 0.18 & 0 & 0 \\
\hline & 0.71 & 0.29 & 0 & 0 \\
\hline \multirow{3}{*}{$\begin{array}{l}\text { LOWER- } \\
\text { MIDDLE }\end{array}$} & 0.06 & 0.79 & 0.15 & 0 \\
\hline & 0.06 & 0.85 & 0.09 & 0 \\
\hline & 0.07 & 0.87 & 0.06 & 0 \\
\hline \multirow{3}{*}{$\begin{array}{l}\text { UPPER- } \\
\text { MIDDLE }\end{array}$} & 0 & 0.16 & 0.81 & 0.03 \\
\hline & 0 & 0.12 & 0.86 & 0.02 \\
\hline & 0 & 0.07 & 0.91 & 0.02 \\
\hline \multirow{3}{*}{$\mathrm{HIGH}$} & 0 & 0 & 0.03 & 0.97 \\
\hline & 0 & 0 & 0.09 & 0.91 \\
\hline & 0 & 0 & 0.16 & 0.84 \\
\hline
\end{tabular}

Before EU accession $\mathrm{x}$ Whole period $\mathbf{x}$ After EU accession

Source Own elaborations based on data collected from Local Data Bank

The analysis of the results in Table 1 may be complemented by an examination of the outcomes shown in Fig. 4, which presents the time evolution of the steady-state distributions in the time-homogenous Markov chains estimated for normalized capital productivity. $^{25}$

As one can see, the steady-state distributions of the time-homogenous Markov chains constructed for normalized capital productivity in the Polish voivodeships showed a tendency to move towards a more concentrated pattern. It is worth stressing that the most-evident change between the pre-EU-accession and post-EU-accession distributions was observed for the LOWER-MIDDLE (a larger share after EU accession) and HIGH classes (a much smaller share after EU accession).

Table 2 present the results of the maximum likelihood estimation of three models of time-homogenous Markov chains constructed for the normalized labor productivity in the Polish voivodeships during the periods of 1995-2004 (pre-EU-accession period), 2004-2015 (post-EU-accession period), and 1995-2015 (full sample).

Irrespective of the period examined, the values of the transition probabilities on the main diagonal are the highest, which once again indicates some persistence in the cross-sectional distribution of labor productivity. However, as compared to the results presented in Table 1, the persistence effect seems much weaker since the diagonal elements of transition matrices are much lower. If we compare the results obtained for the pre-EU-accession and post-EU-accession periods, one can see that

25 All of the transition matrices estimated for capital and labor productivity in the framework of timehomogenous Markov chains turned out to be irreducible, which ensured the existence and uniqueness of the established steady-state distributions (Norris 1998). 


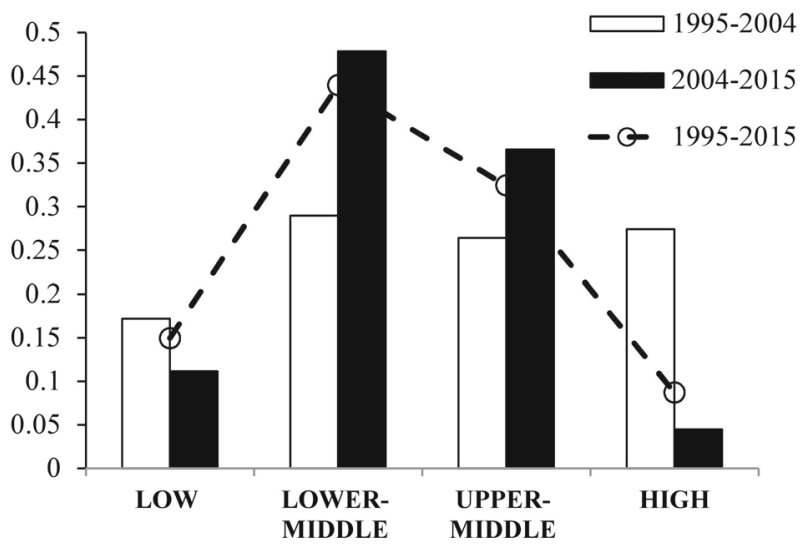

Fig. 4 Time evolution of steady-state distributions in time-homogenous Markov chains constructed for normalized capital productivity in Polish voivodeships Source Own elaborations based on data collected from Local Data Bank

Table 2 Evolution of transition probability matrices in time-homogenous Markov chains constructed for labor productivity in Polish voivodeships

\begin{tabular}{|c||c|c|c|c|}
\cline { 2 - 5 } \multicolumn{1}{c|}{} & LOW & $\begin{array}{c}\text { LOWER- } \\
\text { MIDDLE }\end{array}$ & $\begin{array}{c}\text { UPPER- } \\
\text { MIDDLE }\end{array}$ & HIGH \\
\cline { 2 - 5 } \multicolumn{1}{c|}{} & $\mathbf{0 . 8 7}$ & $\mathbf{0 . 1 3}$ & $\mathbf{0}$ & $\mathbf{0}$ \\
\cline { 2 - 5 } & 0.88 & 0.12 & 0 & 0 \\
\cline { 2 - 5 } & $\mathbf{0 . 8 8}$ & $\mathbf{0 . 1 2}$ & $\mathbf{0}$ & $\mathbf{0}$ \\
\hline \multirow{3}{*}{ LOWER- } & $\mathbf{0 . 0 9}$ & $\mathbf{0 . 8 7}$ & $\mathbf{0 . 0 4}$ & $\mathbf{0}$ \\
\cline { 2 - 5 } MIDDLE & 0.1 & 0.87 & 0.03 & 0 \\
\hline \multirow{3}{*}{ UPPER- } & $\mathbf{0 . 0 9}$ & $\mathbf{0 . 8 9}$ & $\mathbf{0 . 0 2}$ & $\mathbf{0}$ \\
\hline MIDDLE & $\mathbf{0}$ & $\mathbf{0 . 2 4}$ & $\mathbf{0 . 5 8}$ & $\mathbf{0 . 1 8}$ \\
\hline & 0 & 0.18 & 0.59 & 0.23 \\
\hline \multirow{3}{*}{ HIGH } & $\mathbf{0}$ & $\mathbf{0 . 1 7}$ & $\mathbf{0 . 5}$ & $\mathbf{0 . 3 3}$ \\
& $\mathbf{0}$ & $\mathbf{0}$ & $\mathbf{0 . 0 9}$ & $\mathbf{0 . 9 1}$ \\
\hline & 0 & 0 & 0.11 & 0.89 \\
\hline & $\mathbf{0}$ & $\mathbf{0}$ & $\mathbf{0 . 1 1}$ & $\mathbf{0 . 8 9}$ \\
\hline
\end{tabular}

$\mathbf{x}$ Before EU accession $\mathrm{x}$ Whole period $\mathbf{x}$ After EU accession

Source Own elaborations based on data collected from Local Data Bank

the transition probability values in all but the UPPER-MIDDLE class oscillated at around $90 \%$ when compared to the other main-diagonal elements. The relatively low value of the probability of staying in the UPPER-MIDDLE class of normalized labor productivity (around 50\%) implied relatively high probabilities of moving to neighboring classes. Although the probability of moving from the UPPER-MIDDLE to the LOWER-MIDDLE class dropped by around 7\% after EU accession, the probability of moving from the UPPER-MIDDLE to the HIGH class rose by around $15 \%$. All of 


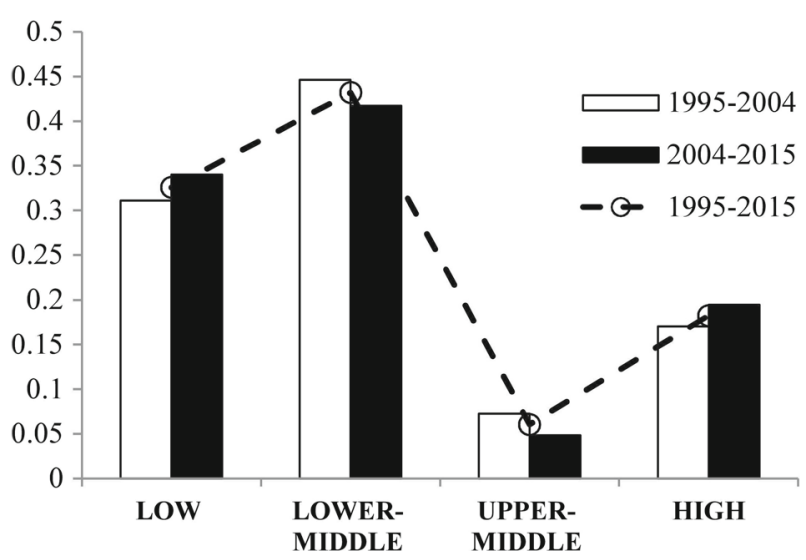

Fig. 5 Time evolution of steady-state distributions in time-homogenous Markov chains constructed for normalized labor productivity in Polish voivodeships Source Own elaborations based on data collected from Local Data Bank

these findings indicate that, after EU accession, the distribution of labor productivity among all Polish voivodeships underwent a strong transformation towards a less concentrated pattern.

The analysis of results contained in Table 2 may be complemented by an examination of the outcomes presented in Fig. 5, which presents the time evolution of the steady-state distributions in the time-homogenous Markov chains for normalized labor productivity.

As one can see, the steady-state distributions of the time-homogenous Markov chains constructed for normalized labor productivity in the Polish voivodeships showed a tendency to move towards a bi-modal pattern. The latter is evidence of the rising divergence in labor productivity, which also potentially indicates polarization and club formation. It is worth stressing that the divergence in labor productivity sped up after EU accession. The latter indicates that the distance between the labor productivity in more-developed voivodeships (especially those located in the central region) and that in the remaining regions of Poland rose significantly when the country accessed the structures of the EU. All of these facts provide solid support for the part of Hypothesis 2 relating to labor productivity.

As mentioned in Sect. 4, fitting and interpreting first-order time-homogenous Markov chains requires several assumptions to be fulfilled, including the timeindependence of the transition matrix. These assumptions may not only be unfulfilled but even untestable for small datasets (Bickenbach and Bode 2001). Therefore, in order to test the stability of the outcomes presented in Tables 1 and 2 and Figs. 4 and 5, we conducted a multistage sensitivity analysis. ${ }^{26}$ First, besides using the MLbased estimators (12), we re-estimated all of the time-homogenous Markov chains

26 One should note that estimating the Markov chains for relatively short subperiods (i.e., pre-EU-accession and post-EU-accession subsamples) is itself a form of a stability analysis since the possible bias caused by time-heterogeneity is less influential for shorter time horizons. On the other hand, one should not forget about the estimation bias caused by small samples. 
using the maximum-likelihood approach with Laplacian smoothing as well as the bootstrap estimators. ${ }^{27}$ In general, neither of these modifications affected the general conclusions resulting from the unmodified ML-based estimators. In the next step of the stability analysis, we went beyond the limitations of the time-homogenous Markov chains and analyzed the non-homogenous discrete-time Markov chains estimated via the maximum a posteriori method implemented using Bayesian inference (Strelioff et al. 2007). This way, we obtained two sets of estimators (one for normalized capital productivity and one for normalized labor productivity), each containing the 18 annual transition matrices defined in (6). ${ }^{28}$ In order to get an overall picture of the changes in the distributions of both types of normalized variables, we calculated the unweighted averages of the respective annual transition matrices for the periods of 1995-2004 (pre-EU-accession period), 2004-2015 (post-EU-accession period), and 1995-2015 (full sample). In general, the averages of the annual transition matrices obtained after the MAP estimation of non-homogenous discrete-time Markov chains turned out to be very similar to the respective transition matrices presented in Tables 1 and 2. Thus, using the non-homogenous models did not affect the general conclusions resulting from the unmodified ML-based time-homogenous estimators. Finally, we tested the robustness of the empirical outcomes to the changes in the choice of the number of states in the discrete Markov models. The discretization grids were redefined in a way that once again ensured that we could obtain a uniform initial distribution of labor and capital productivity for three and five classes. For such choices of the numbers of classes, we then re-estimated the homogenous and non-homogenous Markov chains using unmodified and modified ML estimators. Like the modifications described previously, this type of re-design of the research scenario also led to the formulation of conclusions very similar to those in the benchmark case.

To summarize, the results of the stability analysis strongly confirmed the robustness of the outcomes presented in Tables 1 and 2 and Figs. 4 and 5 to the various changes in the econometric procedures used.

\subsection{Causality from inflow of EU structural funds to capital and labor productivity}

In the last part of the empirical analysis, we formally test whether the evolution of the patterns of the regional technological change described in the two previous subsections could be caused by the inflow of EU structural funds. Given the availability of statistical data, the best that could be done in order to answer this research question was to estimate three bivariate PVAR models in which one of the endogenous variables represented the regional data on the inflow of EU structural funds and the other represented one of the three regional-productivity-related variables (capital productivity (comp. the vertical axis in Fig. 3), labor productivity (horizontal axis in Fig. 3)

\footnotetext{
27 The stabilizing parameter was changed from $\lambda=0.01$ to $\lambda=0.05$ with a step equal to 0.01 . The number of bootstrap samples (parameter $n_{\text {boot }}$ ) also varied from 20 to 50 with a step equal to 10 .

28 In order to save space in this section, we did not provide all of the empirical results and calculations. A summary of the results of the sensitivity analysis are available at the following website: www.zarz.agh.ed u.pl/1lach/Sensitivity_CEJOR_2018.pdf.
} 
Table 3 Results of testing for Granger causality from inflow of EU structural funds to indexes of technological change in Polish regions

\begin{tabular}{|c|c|c|c|c|c|c|}
\hline & \multicolumn{6}{|c|}{ Potential effect } \\
\hline & \multicolumn{2}{|c|}{ Labor productivity } & \multicolumn{2}{|c|}{ Capital productivity } & \multicolumn{2}{|c|}{ Capital-labor ratio } \\
\hline & All regions & $\begin{array}{l}\text { Without } \\
\text { central } \\
\text { region }\end{array}$ & All regions & $\begin{array}{l}\text { Without } \\
\text { central } \\
\text { region }\end{array}$ & All regions & $\begin{array}{l}\text { Without } \\
\text { central } \\
\text { region }\end{array}$ \\
\hline $\begin{array}{l}\text { Null hypothesis: } \\
\text { Structural funds } \\
\text { do not } \\
\text { Granger-cause } \\
\text { potential effect. }\end{array}$ & $\begin{array}{l}\text { 0.032 } \\
\quad[0.017]\end{array}$ & $\begin{array}{l}0.135 \\
\quad[0.121]\end{array}$ & $\begin{array}{l}0.261 \\
\quad[0.287]\end{array}$ & $\begin{array}{l}0.501 \\
\quad[0.481]\end{array}$ & $\begin{array}{l}0.002 \\
{[0.011]}\end{array}$ & $\begin{array}{l}\mathbf{0 . 0 3 2} \\
{[\mathbf{0 . 0 2 2}]}\end{array}$ \\
\hline
\end{tabular}

Notes Numbers in square brackets refer to bootstrap $p$-values. Bold font indicates evidence of significant causality at 5\% significance level. Optimal lag length was found to be equal to 1 (based on Andrews and Lu (2001) algorithm). Moduli of eigenvalues were found to be equal to 0.80 and 0.11 , which confirms stability of the underlying PVAR model

and capital/labor ratio (slope coefficient in Fig. 3)). Since we found some support for Hypothesis 2 in previous subsections, one may expect that the strength of causality between the inflow of EU structural funds and the regional-productivity-related variables could be mainly driven by the nature of these links in the central region. To put this hypothesis to the test, we decided to re-run all of the causality tests after excluding the central region from the sample. This way, one may compare the results of the causality tests obtained for the restricted and unrestricted samples and draw some conclusions on that basis on the role of the central region in shaping the EU structural funds - productivity change relationships. In Table 3, we present the $p$-values obtained while testing for Granger causality using regional data on the Polish economy. ${ }^{29}$

The results presented in Table 3 lead to three main conclusions. First, they confirm that the EU structural funds Granger-caused a capital-labor ratio among the Polish regions, nevertheless the central region was included in the sample or not. ${ }^{30}$ The results obtained for the full sample also provide support for the claim that the EU structural funds were Granger-causing the evolution of labor productivity but not capital productivity. However, we must emphasize that, when the central region was removed from the sample, the respective $p$-value in the test of Granger causality running from the EU structural funds to capital productivity was more than twice as high when compared to the case of the full sample. ${ }^{31}$ The latter indicates that, in the case of the

\footnotetext{
29 Due to the small sample available, we additionally used bootstrap $p$-values obtained after 200 replications. For more details on the bootstrap scheme used, see Abrigo and Love (2016).

30 It is important to underline that, from the operational point of view, the concept of Granger causality is built solely on the statistical properties of a dataset (mainly the structure of correlation between the levels and lags of the variables). Therefore, finding Granger causal links is not equivalent to providing a complete explanation of the nature of the causal links. However, finding significant Granger causality signalizes that a causal mechanism may indeed exist, so-as a consequence-further studies are required to analyze its nature in more detail.

31 From a purely theoretical point of view, the comparison of $p$-values obtained in the models estimated on the basis of the unrestricted and restricted samples is not a fully proper formal method of statistical analysis
} 
central region of Poland, a significant causal link may exist, running from the inflow of EU structural funds to capital productivity. ${ }^{32}$ Similarly, one must stress that, when the central region was removed from the sample, the evidence of causality running from the EU structural funds to labor productivity became statistically insignificant.

Given the results presented in Table 3, one may only list the directions of the statistically significant causal links while the signs of these relationships remain unknown. Therefore, in the next step, we provide plots of the cumulative orthogonal impulse response functions (cIRF) calculated for those directions of causal links that were found to be statistically significant in Table 3.

The results presented in Table 3 as well as the plots of the cIRFs presented in Fig. 6 provide some support for Hypothesis 3 . However, the reliability of these results is somewhat limited due to the small size of the available sample, even when one uses bootstrapped estimates of the variance-covariance matrices. Therefore, to test the reliability of the outcomes presented in Table 3 and Fig. 6, we re-ran all of the Granger causality tests using the voivodeship data. This way, we significantly increased the number of degrees of freedom in the respective PVAR models, as we used data on 16 cross-sectional units (voivodeships) in this case instead of aggregated data on 6 cross-sectional units (regions). In order to test the role of the central region of Poland on shaping the causal links between the EU structural funds and the regional technological progress, we once again decided to run the causality tests in an additional variant, this time with Mazowieckie Voivodeship removed from the sample. ${ }^{33}$ The results of the respective causality tests and the plots of the corresponding cIRFs obtained for the statistically significant causal links are presented in Table 4 and Fig. 7, respectively.

In general, the results presented in Table 4 as well as the plots of the cIRFs presented in Fig. 7 are in line with the outcomes of the analysis of the causal links based on regional data (Table 3, Fig. 6). The only visible difference is that the magnitudes of the plots of the cIRFs in Fig. 7 are smaller when compared to their counterparts presented in Fig. 6. Nevertheless, all of these findings provide rather solid support for the part of Hypothesis 3 related to labor productivity.

A statistically significant (at 5\% significance level) Granger causality running from the inflow of EU structural funds to labor productivity was found only when data on Mazowieckie Voivodeship was included in the sample. Similarly, only when the data on Mazowieckie Voivodeship was included in the sample, the test of Granger causality

\footnotetext{
Footnote 31 continued

(Hofmann and Meyer-Nieberg 2017). However, such an approach seems to be the only reasonable method of getting at least preliminary insights into the analyzed problems. The latter follows from the fact that an alternative approach (i.e., a causality analysis within the framework of the individual region-specific VAR models) is still impossible to perform given the amount of available statistical data.

32 Given the amount of available data, a formal statistical verification of this particular supposition is, however, still impossible.

33 The central region of Poland consists of Mazowieckie Voivodeship (i.e., a voivodeship where the Warsaw Industrial District is located and where the majority of domestic and foreign companies as well as state enterprises have their headquarters) and Łódzkie Voivodeship. However, removing Łódzkie Voivodeship from the sample did not lead to significant changes in the results of the causality analysis compared to the case where the full sample on Polish voivodeships was used. Thus, we decided to report only the results obtained after dropping the data on Mazowieckie Voivodeship.
} 


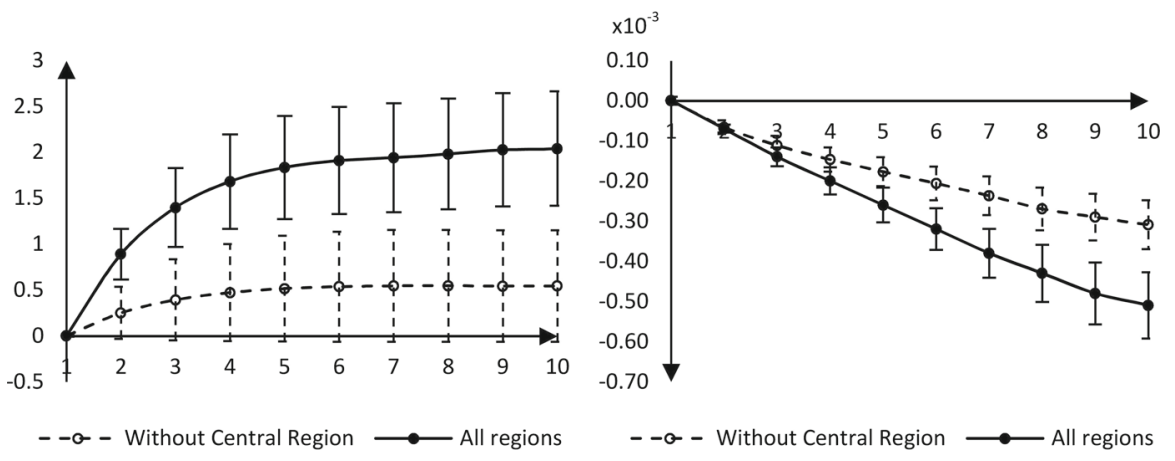

Fig. 6 Cumulative orthogonal impulse responses to one standard deviation shock in inflow of EU structural funds (left panel: response $=$ labor productivity; right panel: response $=$ capital-labor ratio) Note Vertical bars were used to indicate $95 \%$ confidence intervals

Table 4 Results of testing for Granger causality from inflow of EU structural funds to indexes of technological change in Polish voivodeships

\begin{tabular}{|c|c|c|c|c|c|c|}
\hline & \multicolumn{6}{|l|}{ Potential effect } \\
\hline & \multicolumn{2}{|c|}{ Labor productivity } & \multicolumn{2}{|c|}{ Capital productivity } & \multicolumn{2}{|c|}{ Capital-labor ratio } \\
\hline & $\begin{array}{l}\text { All } \\
\text { voivodeships }\end{array}$ & $\begin{array}{l}\text { Without } \\
\text { Mazowieckie } \\
\text { Voivodeship }\end{array}$ & $\begin{array}{l}\text { All } \\
\text { voivodeships }\end{array}$ & $\begin{array}{l}\text { Without } \\
\text { Mazowieckie } \\
\text { Voivodeship }\end{array}$ & $\begin{array}{l}\text { All } \\
\text { voivodeships }\end{array}$ & $\begin{array}{l}\text { Without } \\
\text { Mazowieckie } \\
\text { Voivodeship }\end{array}$ \\
\hline $\begin{array}{l}\text { Null hypothesis: } \\
\text { Structural funds } \\
\text { do not } \\
\text { Ganger-cause } \\
\text { potential effect. }\end{array}$ & $0.013[0.011]$ & $0.172[0.251]$ & $0.181[0.172]$ & $0.453[0.422]$ & $0.000[0.000]$ & $0.009[0.012]$ \\
\hline
\end{tabular}

Note Numbers in square brackets refer to bootstrap $p$-values. Bold font indicates finding significant causality at 5\% significance level. Optimal lag length was found to be equal to 1 (based on Andrews and Lu (2001) algorithm). Moduli of eigenvalues were found to be equal to 0.65 and 0.09 , which confirms stability of underlying PVAR model

running from the inflow of EU structural funds to capital productivity was close to confirming the existence of a statistically significant causal link (a $p$-value around 0.17 compared to a $p$-value close to 0.40 in the case of the restricted dataset).

To summarize, the results of the causality analysis supplement the findings reported in the previous subsections. We found statistically significant evidence to claim that the evolution of regional patterns in technological progress described in the previous subsections (comp. the strong rise in labor productivity in the central region discussed in detail in Sect. 5.1 with the intensification of the bi-modality in the distribution of labor productivity described in Sect. 5.2) was partly driven by the inflow of EU structural funds. 


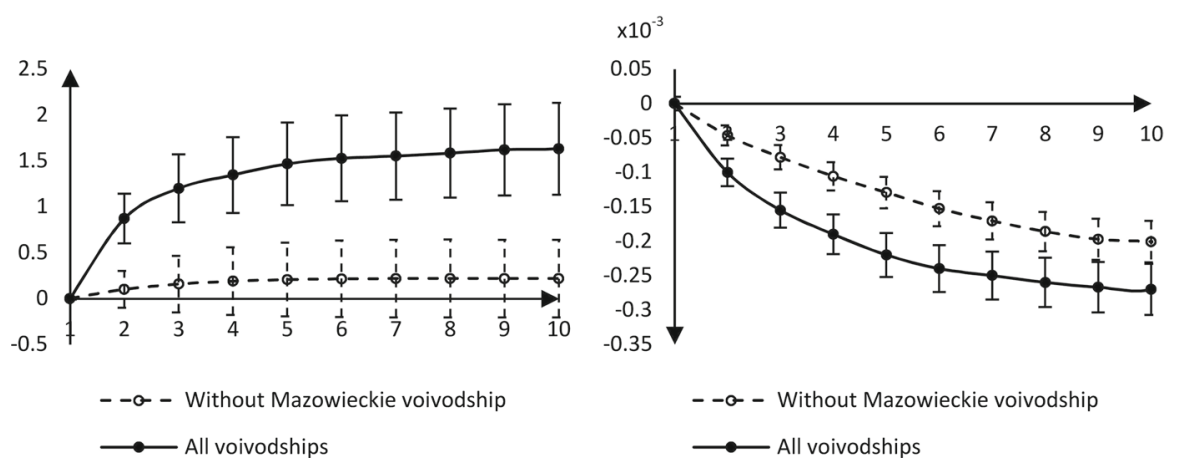

Fig. 7 Cumulative orthogonal impulse responses to one standard deviation shock in inflow of EU structural funds (left panel: response = labor productivity; right panel: response = capital-labor ratio) Note Vertical bars were used to indicate $95 \%$ confidence intervals

\section{Conclusions}

The differences between the directions of the patterns in technological change proved to be modest throughout the investigation period for all Polish regions except for the central region. The latter indicated that, after EU accession, the central region was the only part of Poland that not only reported a fast rise in labor productivity but also managed to constantly increase its capital productivity. As regarding the distributional dynamics of voivodeship capital and labor productivity, the time evolutions of the two distributions were extremely different. By taking a closer look at the aspect of convergence, the results obtained for capital productivity suggest a clear tendency towards a convergence among Polish voivodeships. On the other hand, the results obtained for labor productivity suggest a clear tendency towards divergence, showing that there was a club formation at the high end of the distribution of labor productivity.

In the second part of the empirical analysis, we conducted formal econometric tests that proved that the EU structural funds were a statistically significant cause (in the Granger sense) of the observed evolution of regional patterns of technological change in Poland and, as a consequence, led to an intensification of the bi-modality pattern in the distribution of labor productivity. In the case of labor productivity, the strongest positive causal impact was observed only when the data on the central region of Poland was included in the sample. The latter signalizes that, in the case of the remaining regions of Poland, the impact of the EU structural funds on the evolution of region-specific patterns in technological progress was much weaker. In addition, we found evidence to claim that, of all the Polish regions, the central region (especially Mazowieckie Voivodeship) was able to use the inflow of EU structural funds most efficiently. The latter implied a relative rise not only in labor but also capital productivity compared to the remaining parts of Poland. In our opinion, all of these findings may prove important for future regional policy strategies in Poland, since uncovering the forces behind the differences in the regional patterns of technological change may, in turn, help us better understand the process of the intranational economic catching-up of the lesser developed regions in this country. 
It is likely that many aspects of the differences in the regional economic development in Poland have not been covered in our study, which creates the need for future research. In this context, there are several issues that are of particular interest and could further enrich the understanding of the uneven regional development in Poland. In particular, it would be worthwhile to concentrate an analysis on a sectoral level and properly investigating the aspects related to the structural change in each region as well as at the voivodeship level. Moreover, it also seems promising to study technological change at a more disaggregated sectoral level and to combine the analysis of technological change in the context of regional development with the role played by the regional innovation systems in Poland. Future research could also attempt to further develop the methodological approach used in this paper, including the application of higher-order models and continuous models. All of these potential directions of future research, however, require the availability of significantly more reliable statistical data.

Acknowledgements We would like to thank the editor of this journal (Professor Ulrike LeopoldWildburger) and the anonymous referees for their time and valuable comments on earlier versions of this paper. The financial support for this paper from the National Science Centre of Poland (Research Grant no. DEC-2015/19/B/HS4/00088) is gratefully acknowledged.

Open Access This article is distributed under the terms of the Creative Commons Attribution 4.0 International License (http://creativecommons.org/licenses/by/4.0/), which permits unrestricted use, distribution, and reproduction in any medium, provided you give appropriate credit to the original author(s) and the source, provide a link to the Creative Commons license, and indicate if changes were made.

\section{References}

Abrigo MRM, Love I (2016) Estimation of panel vector autoregression in Stata. Stata J 16(3):778-804

Anderson TW, Goodman LA (1957) Statistical inference about Markov Chains. Ann Math Stat 28(1):89-110

Andrews DWK, Lu B (2001) Consistent model and moment selection procedures for GMM estimation with application to dynamic panel data models. J Econom 101(1):123-164

Atkinson A, Morelli S (2014) Chartbook of economic inequality. ECINEQ Working Paper 324

Barro RJ, Sala-I-Martin X (1991) Convergence across States and Provinces. Brookings Pap Econ Act 1:107-182

Barro RJ, Sala-I-Martin X (1992) Convergence. J Polit Econ 100:407-443

Bickenbach F, Bode E (2001) Markov or not Markov-this should be a question. Working Paper, Kiel Institute of World Economics

Bickenbach F, Bode E (2003) Evaluating the Markov property in studies of economic convergence. Int Reg Sci Rev 26:363-392

Bliss C (1999) Galton's fallacy and economic convergence. Oxford Econ Pap 51(1):4-14

Bulli S (2001) Distribution dynamics and cross-country convergence: a new approach. Scott J Polit Econ 48:226-243

Bun MJG, Carree MA (2005) Bias-corrected estimation in dynamic panel data models. J Bus Econ Stat 23(2):200-210

Canova F, Ciccarelli M (2013) Panel vector autoregressive models: a survey. In: Fomby TB, Lutz K, Kilian MA (eds) VAR models in macroeconomics-new developments and applications: essays in honor of Christopher A. Sims (Advances in Econometrics), vol 32. Emerald Group Publishing Limited, Bingley, pp 205-246

Chocholatá M, Furková A (2017) Does the location and the institutional background matter in convergence modelling of the EU regions? CEJOR 25(3):679-697

Czyż T, Hauke J (2011) Evolution of regional disparities in Poland. Quaest Geogr 30(2):35-48

Di Cataldo M (2017) The impact of EU objective 1 funds on regional development: evidence from the U.K. and the prospect of Brexit. J Reg Sci. https://doi.org/10.1111/jors.12337 
Durlauf S, Quah D (1998) The new empirics of economic growth. CEP discussion paper; CEPDP0384, 384. Centre for Economic Performance. London School of Economics and Political Science, London, UK

Everaert G, Pozzi L (2007) Bootstrap-based correction for dynamic panels. J Econ Dyn Control 31(4):1160-1184

Ferretti F (2008) Patterns of technical change: a geometrical analysis using the wage-profit rate schedule. Int Rev Appl Econ 22(5):565-583

Foley D, Marquetti A (1997) Economic growth from a classical perspective. In: Teixeira J (ed) Money, growth, distribution and structural change: contemporaneous analysis. University of Brasilia Press, Brasilia

Foley D, Michl T (1999) Growth and distribution. Harvard University Press, Cambridge

Friedman M (1992) Do old fallacies ever die? J Econ Lit 30(4):2129-2132

Gelman A (2005) Analysis of variance-Why it is more important than ever. Ann Stat 33:1-53

Goldsmith RW (1951) A perpetual inventory of national wealth. Studies in Income and Wealth (14), NBER

Gorzelak G (2006) Poland's regional policy and disparities in the Polish Space. Reg Local Stud 7:39-74

Grabek G, Klos B, Koloch G (2011) SOEPL 2009—an estimated dynamic stochastic general equilibrium model for policy analysis and forecasting. National Bank of Poland Working Papers 83, National Bank of Poland, Economic Institute

Gurgul H, Lach $€$ (2011) The impact of regional disparities on economic growth. Oper Res Dec 22(2):37-63

Hierro M, Maza A (2010) Per capita income convergence and internal migration in Spain: are foreign-born migrants playing an important role? Pap Reg Sci 89(1):89-107

Hofmann M, Meyer-Nieberg S (2017) Time to dispense with the $p$-value in OR? CEJOR. https://doi.org/1 $0.1007 / \mathrm{s} 10100-017-0484-9$

Islam N (2003) What have we learnt from the convergence debate? J Econ Surv 17(3):309-362

Kramulová J, Jablonský J (2016) AHP model for competitiveness analysis of selected countries. CEJOR 24(2):335-351

Lenain P (2000) Poland's successful transition. OECD Observer (220). http://www.oecdobserver.org/new s/archivestory.php/aid/212/Polands_successful_transition.html. Accessed on 10.10.2017

Lobatch A (2004) EU membership and growing regional disparities: Poland's strategy options to optimize structural transfers from the union. Paper presented at the 12th NISPAcee annual conference "Central and Eastern European countries inside and outside the European Union: avoiding a new divide", Vilnius, Lithuania, 13-15 May 2004

Magrini S (1999) The evolution of income disparities among the regions of the European Union. Reg Sci Urban Econ 29(2):257-281

Norris JR (1998) Markov Chains. Cambridge University Press, Cambridge

Quah D (1993a) Empirical cross-section dynamics in economic growth. Eur Econ Rev 37:426-434

Quah D (1993b) Galton's Fallacy and tests of the convergence hypothesis. Scand J Econ 95:427-443

Quah D (1996a) Convergence empirics across economies with (some) capital mobility. J Econ Growth $1: 95-124$

Quah D (1996b) Regional convergence clusters across Europe. Eur Econ Rev 40:951-958

Quah D (1997) Empirics for growth and distribution: stratification, polarization, and convergence clubs. J Econ Growth 2:27-59

Schütz M, Li H, Palan N (2017) Are central and western Chinese Provinces catching up with the east? An empirical analysis of convergence processes across China. Front Econ China 12(4):571-606

Strelioff CC, Crutchfield JP, Hübler AW (2007) Inferring Markov chains: Bayesian estimation, model comparison, entropy rate, and out-of-class modeling. Phys Rev E 76:011106. http://arxiv.org/math.S T/0703715

Vaona A (2011) Profit rate dynamics, income distribution, structural and technical change in Denmark, Finland and Italy. Struct Change Econ Dyn 22(3):247-268 